REVIEW

\title{
SURFACTINA: ESTRUTURA, APLICAÇÕES E FATORES ENVOLVIDOS EM SUA PRODUÇÃO
}

\author{
Larini $\mathrm{MM}^{*}$, Rezende $\mathrm{MI}^{* *}$, Ribeiro MLL***, Moreira-Gasparin FG****
}

\begin{abstract}
Resumo
A surfactina é um lipopeptídeo da classe dos biossurfactantes, mais comumente produzida por Bacillus subtilis, uma bactéria Gram-positiva. A estrutura química da surfactina é composta por peptídeo ligado aos grupos carboxil e hidrocarboxil de ácidos graxos de cadeia longa. A produção de surfactina pode ser influenciada pela linhagem, inóculo e idade do microrganismo, além de fatores físicos como temperatura, pH, velocidade de agitação, grau de aeração, formação de espuma e concentração de oxigênio dissolvido e fatores nutricionais, como fontes de carbono, nitrogênio e elementos-traço nos meios de cultivo. As potenciais áreas de aplicação desse biossurfactante são terapêuticas e ambientais.
\end{abstract}

\footnotetext{
* Mestre em Biotecnologia pela Universidade Estadual de Londrina; Pós-graduada em Química para Educação Básica pela Universidade Estadual de Londrina; marianamlarini@gmail.com

** Doutora em Ciências Biológicas pela Universidade Estadual Paulista Júlio de Mesquita Filho; Mestre em Microbiologia pela Universidade Estadual de Londrina; Professora do Departamento de Bioquímica e Biotecnologia na Universidade Estadual de Londrina; mirezende@uel.br

*** Doutora e Mestre em Ciência de Alimentos pela Universidade Estadual de Londrina; Professora do Departamento de Bioquímica e Biotecnologia na Universidade Estadual de Londrina; maraluciaribeiro@uel.br

**** Doutora em Mestre em Ciências Biológicas pela Universidade Estadual de Maringá; Professora do Departamento de Bioquímica e Biotecnologia na Universidade Estadual de Londrina; fagasparin@uel.br
} 
Neste trabalho tem-se como objetivo abordar aspectos estruturais, fatores envolvidos na produção por microrganismos e as áreas de aplicação da surfactina.

Palavras-chave: Aplicações. Estrutura. Microrganismos. Produção. Surfactina.

\section{Surfactin: structure, applications and factors involved in its production}

\section{Abstract}

Surfactin is a lipopeptide of the biosurfactant class, most commonly produced by Bacillus subtilis, a Gram-positive bacterium. The chemical structure of surfactin is composed of peptide bound to carboxyl groups and hydrocarboxyl of long chain fatty acids. Surfactin production may be influenced by the strain, inoculum and age of the microorganism, as well as physical factors such as temperature, $p H$, agitation speed, aeration degree, foam formation and dissolved oxygen concentration and nutritional factors, such as carbon, nitrogen and trace elements in the culture media. The potential areas of application of this biosurfactant are therapeutic and environmental. This work aims to address structural aspects, factors involved in production by microorganisms and the application areas of surfactin.

Keywords: Applications. Structure. Microorganisms. Production. Surfactin.

\section{INTRODUÇÃO}

Os surfactantes são compostos anfipáticos capazes de reduzir a tensão superficial e interfacial entre moléculas individuais em suas superfícies e interfaces, ${ }^{1}$ propriedade que tem aplicabilidade na indústria, agricultura, mineração e recuperação de petróleo. Também podem atuar como agentes umedecedores, espumantes e emulsionantes na indústria farmacêutica e cosmética. O mercado mundial tem crescido e foi avaliado em US\$ 30,65 bilhões no ano 2015, e espera-se atingir US\$ 39,69 bilhões em 2021 e US\$ 45,16 bilhões até $2024 .^{2}$

Os biossurfactantes, sintetizados por microrganismos ou por biotecnologia enzimática, apresentam potencial para substituir os surfactantes químicos. Porém, o custo associado à sua produção é superior ao do surfactante sintético, sendo este um fator que limita a sua utilização na indústria. Todavia, a utilização de biossurfactantes é promissora em produtos de elevado valor agregado, como cosméticos e medicamentos. ${ }^{3}$

A surfactina foi relatada pela primeira vez em estudo em que se pesquisou um inibidor da formação do coágulo de fibrina e se isolou um lipopeptídeo cristalino de um cultivo de B. subtilis com potente ação inibidora da formação de coágulo e como agente tensoativo de superfície. ${ }^{4}$ A surfactina diluída em água destilada (0,005\%) reduziu a tensão superficial da água de $72 \mathrm{mN} \mathrm{m}^{-1}$ para $27 \mathrm{mN}$ $\mathrm{m}^{-1}$, e esse resultado foi superior ao observado para o lauril sulfato de sódio, um surfactante sintético. ${ }^{5}$ Além disso, a surfactina promoveu a redução da tensão interfacial do sistema água/hexadecano de 43 $\mathrm{mN} \mathrm{m}^{-1}$ a valores menores que $1 \mathrm{mN} \mathrm{m}^{-1}$, com concentração micelar crítica (CMC) de $10^{-5} \mathrm{M}$. A CMC 
indica a mínima concentração de surfactante com propriedades tensoativas, sendo que, a partir desta, inicia-se a formação de micelas que conferem as propriedades de detergência e solubilização do composto. ${ }^{6}$

Os biossurfactantes apresentam vantagens, como biodegradabilidade, produção a partir de substratos renováveis, baixa toxicidade, biocompatibilidade, digestibilidade, diversidade de estrutura química e efetividade em condições extremas de temperatura, $\mathrm{pH}$ e salinidade, considerando-se uma alternativa real de substituição aos surfactantes. ${ }^{7}$

\section{CARACTERÍSTICAS ESTRUTURAIS}

Os biossurfactantes são classificados, conforme a estrutura química, em lipopeptídeos, glicolipídeos, lipoproteínas, fosfolipídeos, ácidos graxos, lipídeos neutros e compostos poliméricos. Os lipopeptídeos contêm peptídeos hidrofílicos de sete a 10 aminoácidos que diferem na composição e sequência, ligados a um ácido graxo hidrofóbico com diferentes comprimentos de cadeia, e estão entre os principais biossurfactantes produzidos por Bacillus spp. e caracterizados. Em relação à sequência de aminoácidos, eles podem ser classificados em iturinas, fengicinas e surfactinas. ${ }^{8}$

A estrutura primária da surfactina foi determinada por Kakinuma et al. ${ }^{9}$ e é composta por um peptídeo de sete $\alpha$-aminoácidos ligados a uma cadeia de ácido graxo $\beta$-hidroxi com 12 a 16 átomos de carbono, formando um lipopeptídeo cíclico. ${ }^{9}$

As surfactinas possuem análogos estruturais ou isoformas $\mathrm{A}, \mathrm{B}$ e C, conforme a sequência de aminoácidos e o número de átomos de carbono do ácido graxo. ${ }^{9} \mathrm{~A}$ surfactina A é a principal isoforma e apresenta a sequência de resíduos de aminoácidos N-L-Glu-L-Leu-D-Leu-L-Val-L-Asp-D-Leu-L-Leu-C em sua porção peptídica e difere no sétimo aminoácido, sendo Val e Ile para as isoformas B e C. ${ }^{10}$ A composição da porção peptídica e de ácidos graxos $\beta$-hidróxi da molécula dependem das linhagens bacterianas produtoras e das condições de cultivo. ${ }^{11}$

Pesquisadores cultivaram $B$. subtilis HSO121 e identificaram três surfactinas com diferentes porções peptídicas, sendo surfactina A (N-Glu-Leu-Leu-Val-Asp-Leu-Leu-C), uma surfactina com a sequência N-Asp-Leu-Leu-Val-Glu-Leu-Leu-C e outra com uma cadeia peptídica metil esterificada. ${ }^{12}$ Os ácidos graxos identificados foram $\beta$-hidróxi iso $\mathrm{C}_{12}$, iso $\mathrm{C}_{13}$, anteiso $\mathrm{C}_{13}$, iso $\mathrm{C}_{14}$, iso $\mathrm{C}_{15}$, anteiso $\mathrm{C}_{15}$, $\mathrm{n}_{15}$, anteiso $\mathrm{C}_{16}$ e anteiso $\mathrm{C}_{17}$.

Novas moléculas de surfactina, o lipopeptídeo $C_{12}$, com menor comprimento de cadeia de ácido graxo, e o $\mathrm{C}_{15}$-surfactina-O-metil éster, um lipopeptídeo esterificado, foram isolados e identificados ao se cultivar B. subtilis HSO $121 .{ }^{10}$ As porções de ácido graxo do $\mathrm{C}_{15}$-surfactina-O-metil éster foram identificadas como ácidos graxos $\beta$-hidróxi iso $\mathrm{C}_{15}$ e anteiso $\mathrm{C}_{15}$. $\mathrm{O}$ anel peptídico foi analisado, e a sequência de aminoácido de N-Glu(OMe)-Leu-Leu-Val-Asp-Leu-Leu-C foi identificada.

As pesquisas indicam que diferentes linhagens bacterianas podem produzir o mesmo tipo de surfactina, mesmas linhagens sintetizam diferentes lipopeptídeos, ${ }^{13}$ e as diferenças nas propriedades físico-químicas em séries homólogas e isoformas desses compostos podem afetar a aplicação e a 
efetividade dessas biomoléculas, sendo necessário avaliar suas propriedades funcionais, toxicidade e adequação para aplicação industrial. ${ }^{7}$

\section{PRODUÇÃO DE SURFACTINA}

Para compreender o processo pelo qual os microrganismos produzem surfactina, nesta seção apresentam-se vários aspectos de sua produção, incluindo as condições de cultivo e composição dos meios utilizados. Entre os fatores que afetam a produção de surfactina, tem-se: tipo de microrganismo, condições físicas e nutricionais e substratos utilizados na produção.

\subsection{MICRORGANISMOS PRODUTORES}

O Bacillus subtilis tem sido amplamente estudado e é o microrganismo mais importante para a produção de surfactina. ${ }^{14,5}$ Os B. subtilis são bastonetes, Gram-positivos, encontradas em solo e vegetação, crescem na temperatura entre 25 e $37^{\circ} \mathrm{C}$ e são capazes de desenvolver estratégias que permitem sua sobrevivência em condições extremas, como estresse ambiental e falta de nutrientes. ${ }^{3} \mathrm{Na}$ Tabela 1 observam-se as linhagens de B. subtilis empregadas para a produção de surfactina, os substratos utilizados e as concentrações obtidas.

Tabela 1 - Linhagens de Bacillus subtilis produtoras de surfactina, os substratos utilizados e as concentrações obtidas

\begin{tabular}{|c|c|c|c|}
\hline $\begin{array}{c}\text { Linhagens de } \\
\text { Bacillus sub- } \\
\text { tilis }\end{array}$ & Substrato & Concentração de surfactina & Referência \\
\hline SPB1 & Glicose, ureia, cloreto de amônio e querosene & 4,920 g. $\mathrm{L}^{-1}$ & [15] \\
\hline DSM $10^{\mathrm{T}}$ & Glicose, $\mathrm{Na}_{3}$ trissódico e $\left(\mathrm{NH}_{4}\right)_{2} \mathrm{SO}_{4}$ & 1,100 g. $\mathrm{L}^{-1}$ & [16] \\
\hline LSFM-05 & Glicerol & 0,230 g. $L^{-1}$ & [17] \\
\hline ATCC 6633 & Glicerol & $0,158 \mathrm{~g} \cdot \mathrm{L}^{-1}$ & [18] \\
\hline \#573 & Milhocina & 1,300 g. $L^{-1}$ & [19] \\
\hline BS-37 & $\begin{array}{l}\text { Meio Luria Bertrani (LB) } \\
\text { Meio de glicose }\end{array}$ & $\begin{array}{l}0,413 \mathrm{~g} \cdot \mathrm{L}^{-1} \\
0,585 \mathrm{~g} \cdot \mathrm{L}^{-1}\end{array}$ & [13] \\
\hline MTCC 2423 & $\begin{array}{l}\text { Glicose } \\
\text { Resíduo de óleo de girassol } \\
\text { Resíduo de óleo de farelo de arroz }\end{array}$ & $\begin{array}{r}0,021 \mathrm{~g} \mathrm{~g}^{-1} \text { glicose } \\
1,490 \mathrm{~g} \mathrm{~g}^{-1} \text { substrato } \\
0,010 \mathrm{~g} \mathrm{~g}^{-1} \text { substrato }\end{array}$ & [20] \\
\hline
\end{tabular}

Outras espécies de Bacillus foram relatadas como produtoras de surfactina, como o B. pumilus UFPEDA $448^{6}$ e o Virgibacillus salarius. ${ }^{21}$ 


\subsection{PRINCIPAIS PARÂMETROS DE PRODUÇÃO}

\subsubsection{Condições físicas}

As condições físicas de cultivo, como temperatura, concentração de oxigênio dissolvido e grau de aeração afetam o crescimento celular e, portanto, influenciam a produção de surfactina.

A temperatura do meio de cultivo influencia significativamente a produção de surfactina por B. subtilis. A surfactina é secretada a temperaturas entre 25 e $37{ }^{\circ} \mathrm{C} .{ }^{14,22}$ Sen e Swaminathan ${ }^{22}$ verificaram que $37,4^{\circ} \mathrm{C}$ foi a temperatura ótima para a produção de surfactina pelo B. subtilis DSM 3256.

A eficiência do oxigênio dissolvido e da transferência de massa afeta a produção de surfactina por B. subtilis. ${ }^{14}$ Ghribi e Ellouze-Chaabouni ${ }^{15}$ constataram que uma maior produção de surfactina foi obtida em meio saturado com $30 \%$ de oxigênio dissolvido.

Estudos mostraram que o aumento da concentração de oxigênio dissolvido por agitação rápida influenciou positivamente a produção de surfactina por B. subtilis. A velocidade de agitação afetou a produção, e o melhor rendimento foi obtido com 200 a $250 \mathrm{rpm} .{ }^{14} \mathrm{O}$ acúmulo de espuma é outro fator crítico que afeta a produção de surfactina e seu efeito está relacionado com aeração. A agitação superior a $250 \mathrm{rpm}$ acumulou espuma, diminuiu a transferência de oxigênio, a biomassa e o rendimento de surfactina pela diminuição do período de fermentação. ${ }^{14}$

O coeficiente volumétrico de transferência de massa, kLa, afeta significativamente a produção de biossurfactante. Os principais parâmetros que influenciam os valores de kLa são a velocidade superficial do líquido e do gás, a tensão superficial do meio líquido e a presença de partículas sólidas. ${ }^{3}$ Em pesquisa em que se utilizou um biorreator trifásico de fase reversa de leito fluidizado para discutir o efeito do kLa na produção de surfactina por B. subtilis, observou-se que as velocidades superficiais do gás e do líquido reduzidas diminuem a transferência de oxigênio e aumentam a produção de surfactina. ${ }^{23}$

Outras condições de cultivo, como tamanho e idade do inóculo, também influenciam a produção de surfactina, em razão de que afetam o período da fase lag, a taxa de crescimento específica, a biomassa e a esporulação. ${ }^{15}$

\subsubsection{Condições nutricionais}

\subsubsection{Fontes de carbono e de nitrogênio}

Fontes de carbono (glicose, manitol e sacarose) e de nitrogênio orgânico (ureia, triptona, digerido pancreático de caseína, hidrolisado de caseína, extrato de carne e extrato de levedura) ou inorgânico $\left(\mathrm{NH}_{4} \mathrm{Cl}, \mathrm{NaNO}_{3}\right.$ e $\left.\left(\mathrm{NH}_{4}\right)_{2} \mathrm{SO}_{4}\right)$ podem ser usados para a produção de surfactina por Bacillus.

A produção de surfactina foi de $4,92 \mathrm{~g}$. $\mathrm{L}^{-1}$ quando o $B$. subtilis SPB1 foi cultivado em meio contendo $40 \mathrm{~g}$. $\mathrm{L}^{-1}$ de glicose, como fonte de carbono, e $5 \mathrm{~g}$. $\mathrm{L}^{-1}$ de ureia, como fonte de nitrogênio orgânico, e razão $\mathrm{C} / \mathrm{N}$ de 7 com $2 \%$ de querosene e cloreto de amônio, como fonte de nitrogênio inorgânico. Ao avaliar somente o efeito das fontes de nitrogênio (ureia, caseína hidrolisada enzimaticamente, 
extrato de carne, extrato de levedura e hidrolisado de caseína), a produção de surfactina foi de 0,72 g. $\mathrm{L}^{-1}$, com ureia como melhor fonte de nitrogênio. ${ }^{15}$ Pesquisadores observaram que a diminuição de glicose de $40 \mathrm{~g}$. L $\mathrm{L}^{-1}$ para $8 \mathrm{~g}$. L $\mathrm{L}^{-1} \mathrm{e}$ a substituição de EDTA por citrato de sódio aumentaram a produção de surfactina de 0,700 para $1,100 \mathrm{~g}$. $\mathrm{L}^{-1}$ quando cultivaram o B. subtilis DSM $10^{\mathrm{T}}$ em frascos agitados. ${ }^{16}$

Em pesquisa na qual se cultivou o $B$. subtilis LSFM-05 em glicerol bruto obtido do biodiesel como única fonte de carbono, a produção foi realizada em fermentador de bancada de $15 \mathrm{~L}$, e a surfactina foi obtida e purificada a partir da espuma coletada, com rendimento de $0,23 \mathrm{~g}$. $\mathrm{L}^{-1} \mathrm{de}$ espuma coletada. ${ }^{17}$ No cultivo das linhagens de B. subtilis LAMI005 e LAMI009 em glicerol 2\% (v/v) como principal fonte de carbono, obteve-se $0,441 \mathrm{~g}$. $\mathrm{L}^{-1}$ e $0,267 \mathrm{~g}$. $\mathrm{L}^{-1}$ de surfactina, enquanto o B. subtilis ATCC 6633 produziu $0,158 \mathrm{~g}$. $\mathrm{L}^{-1}$ após 72 horas de fermentação. ${ }^{18}$

Um estudo com carvão ativado suplementado com glicose como fonte de carbono nas concentrações de 40, 50 e $60 \mathrm{~g}$. L-1 constatou que a melhor produção de surfactina foi de 3,6 g. L-1 para a menor concentração de glicose. O aumento na concentração de glicose diminuiu o pH do meio e a produção de surfactina de $3,6 \mathrm{~g} \cdot \mathrm{L}^{-1}$ para $2,7 \mathrm{~g} \cdot \mathrm{L}^{-1} \cdot{ }^{14}$

\subsubsection{Elementos-traço}

Os elementos-traço $\mathrm{Mg}^{2+}, \mathrm{K}^{+}, \mathrm{Mn}^{2+}$ e $\mathrm{Fe}^{2+}$ são particularmente importantes na biossíntese de surfactina por B. subtilis por atuarem como cofatores principais em sistemas multienzimáticos envolvidos nesse processo. ${ }^{3}$

Estudos mostraram que $\mathrm{Mg}^{2+}, \mathrm{K}^{+}, \mathrm{Fe}^{2+}$ e $\mathrm{Mn}^{2+}$ foram efetivos na produção de surfactina por B. subtilis ATCC 21332, com rendimento de 1,6 g. $\mathrm{L}^{-1} \cdot{ }^{24} \mathrm{Na}$ ausência de $\mathrm{Mg}^{2+}$ ou K $\mathrm{K}^{+}$e $\mathrm{Mn}^{2+} \mathrm{e} \mathrm{Fe}^{2+}$ o rendimento diminuiu para 0,4 g. $\mathrm{L}^{-1}$ e $0,6 \mathrm{~g}$. $\mathrm{L}^{-1}$, respectivamente. Quando $\mathrm{Fe}^{2+} \mathrm{ou} \mathrm{Mn}^{2+}$ estavam ausentes, o B. subtilis ATCC 21332 produziu $80 \%$ da surfactina inicial. Para avaliar os efeitos da interação entre $\mathrm{Mg}^{2+}, \mathrm{K}^{+}, \mathrm{Mn}^{2+}, \mathrm{Fe}^{2+}$ na produção de surfactina foi utilizado o método estatístico Taguchi. Os resultados indicaram que a interação de $\mathrm{Mg}^{2+}$ e $\mathrm{K}^{+}$promoveu um aumento na produção de surfactina para 3,34 g. $\mathrm{L}^{-1}$, aproximadamente o dobro do rendimento inicial.

No cultivo de B. subtilis \#573 em milhocina, avaliou-se o efeito de $\mathrm{Fe}^{2+}, \mathrm{Mg}^{2+}$ e $\mathrm{Mn}^{2+}$ na produção de surfactina e observou-se aumento na produção para 4,1, 4,4 e 3,5 g. $\mathrm{L}^{-1} \cdot{ }^{19} \mathrm{O}$ melhor resultado foi de $1,3 \mathrm{~g}$. $\mathrm{L}^{-1}$ em meio de cultura contendo $10 \%(\mathrm{v} / \mathrm{v})$ de milhocina, considerando que, quando o meio foi suplementado com os três íons simultaneamente, a produção de surfactina foi aumentada para $4,8 \mathrm{~g}$. L ${ }^{-1}$.

\subsection{SUBSTRATOS COMPLEXOS}

Resíduos agroindustriais, águas residuárias e restos de alimentos são substratos complexos que podem ser utilizados para a produção de metabólitos microbianos, contribuindo para a dimi- 
nuição desses resíduos no meio ambiente. Na Tabela 2 observa-se a diversidade de subprodutos da agroindústria utilizados na produção de surfactina por Bacillus.

Tabela 2 - Resíduos da agroindústria e outros substratos complexos utilizados na produção de surfactina por Bacillus

\begin{tabular}{lccc}
\hline \multicolumn{1}{c}{ Microrganismo } & Substrato & Surfactina $\left(\mathbf{g} . \mathbf{L}^{-\mathbf{1}}\right)$ & Referência \\
\hline B. subtilis \#573 & Milhocina & 1,300 & {$[19]$} \\
B. subtilis ATCC 6633 & & 0,158 & {$[18]$} \\
B. subtilis LSFM-05 & Glicerol & 0,230 & {$[17]$} \\
B. subtilis LAMI005 & & 0,441 & 0,267 \\
e LAMI009 & & 0,983 & {$[20]$} \\
B. subtilis MTCC 2423 & Resíduos de óleo de fritura & & \\
\hline
\end{tabular}

Além dos substratos citados na Tabela 2, também foi relatado o uso de resíduos hidrolisados da agroindústria para a obtenção de surfactina e soforolipídeos, outra classe de biossurfactantes, por diferentes microrganismos (Tabela 3).

Tabela 3 - Resíduos da agroindústria hidrolisados utilizados como substrato para a produção de biossurfactantes por diferentes microrganismos

\begin{tabular}{|c|c|c|c|}
\hline Microrganismo & Substrato & $\begin{array}{c}\text { Biossurfactante } \\
\left.(\text { g. L L })^{-1}\right)\end{array}$ & Referência \\
\hline Starmerella bombicola NBRC 10243 & Hidrolisado de espiga de milho & $\begin{array}{l}\text { Soforolipídeos } \\
49,2\end{array}$ & {$[25]$} \\
\hline B. subtilis ATCC 21332 & Hidrolisado de celulose do sisal & $\begin{array}{l}\text { Surfactina } \\
\text { Não informado }\end{array}$ & {$[26]$} \\
\hline Lactobacillus pentosus & Hidrolisado do bagaço de uva & $\begin{array}{l}\text { Surfactina } \\
4,8 \times 10^{-3}\end{array}$ & {$[27]$} \\
\hline
\end{tabular}

Ghribi e Ellouze-Chaabouni ${ }^{15}$ cultivaram o B. subtilis SPB1 para produção de surfactina, e os resultados foram 1,00 g. $\mathrm{L}^{-1}$ (azeite de oliva), 1,10 g. $\mathrm{L}^{-1}$ (óleo de girassol), 1,10 g. L $\mathrm{L}^{-1}$ (óleo de milho), 1,30 g. L-1 (parafina), 1,74 g. L'-1 (querosene), 1,50 g. L-1 (óleo diesel), 1,00 g. L-1 (benzeno) e 1,20 g. L ${ }^{-1}$ (heptano).

\section{APLICAÇÕES}

As surfactinas podem apresentar diferentes aplicações. Na Tabela 4 observam-se as aplicações ambientais, o biocontrole e as terapêuticas da surfactina. 
Tabela 4 - Aplicações ambientais e terapêuticas da surfactina

\begin{tabular}{lcc}
\hline \multicolumn{1}{c}{ Atividade } & \multicolumn{1}{c}{ Aplicações ambientais } & Referências \\
\hline $\begin{array}{l}\text { Biorremediação ambiental } \\
\text { Biodegradação de hidrocarbonetos }\end{array}$ & Atividades de superfície e emulsificantes & {$[1,28]$} \\
& \multicolumn{1}{c}{ Biocontrole } & {$[1,29]$} \\
Biocontrole & Atividade bactericida induzindo a imunidade da planta & {$[30]$} \\
& Aplicações terapêuticas & {$[31]$} \\
Antimicoplasma & & {$[11]$} \\
Antiviral & Induz a formação de canais Iônicos em membranas de & {$[11,5]$} \\
Antibacteriana & bicamada lipídica \\
Antiinflamatória & Inibição da fosfolipase citosólica plaquetária & \\
Antiadesiva & Inibição da formação de biofilme &
\end{tabular}

\subsection{APLICAÇÕES AMBIENTAIS}

Derramamentos de petróleo nos ambientes marinhos são uma das importantes causas de poluição. Em razão da toxicidade e persistência, os surfactantes sintéticos não são adequados como agentes de remediação. ${ }^{13}$ Os microrganismos sintetizam uma variedade de bioemulsificantes de diferente massa molecular, como os glicolipídeos (trealose, soforolipídeos e ramnolipídeos) e os lipopeptídeos (gramicidina S, polimixina e surfactina). Esses bioemulsificantes apresentam aplicação comercial em biorremediação de solo e água contaminados por petróleo. ${ }^{32}$

As surfactinas apresentam atividade de superfície e emulsificação que favorecem sua aplicação ambiental, o melhoramento da recuperação de petróleo e os processos de biorremediação. ${ }^{33}$

A recuperação microbiológica avançada de petróleo - do inglês Microbial enhanced oil recovery (MEOR) - é considerada uma tecnologia de recuperação de petróleo terciária, que usa microrganismos e seus metabólitos para mobilizar o petróleo residual, ou seja, aquele que está preso nos poros das rochas por força capilar. O uso de surfactina em $M E O R$ é promissor, pois esse biossurfactante apresenta vantagens eficazes, incluindo baixa toxicidade, maior biodegradabilidade e efetividade em temperaturas, salinidade e condições de $\mathrm{pH}$ extremas, bem como alta atividade interfacial aliada à baixa CMC. ${ }^{33}$

A surfactina produzida por B. subtilis MTCC 2423 cultivado a $45^{\circ} \mathrm{C}$ apresentou CMC de 35 mg. $\mathrm{L}^{-1}, 90 \%$ de Índice de Emulsificação $\left(\mathrm{IE}_{24}\right)$ com oléo diesel e recuperou $62 \%$ do petróleo retido em areia. ${ }^{34}$ Esses resultados mostram que a surfactina apresenta potencial em MEOR ao forçar o deslocamento e facilitar o transporte do óleo das formações geológicas. Em pesquisa em que se cultivou o B. subtilis ATCC 21332 em concentração de $\mathrm{NaCl}$ de 0 a 10\%, pH de 3 a 10 e temperaturas entre 21 e $70{ }^{\circ} \mathrm{C}$ para produção de surfactina, avaliou-se sua atividade pela medida de redução de tensão superficial. ${ }^{35}$ No estudo concluiu-se que cada um dos parâmetros, individuais ou a combinação deles, 
resultaram em mudanças na atividade de surfactina, indicando que esta pode ser explorada como um agente em $M E O R$.

Métodos de avaliação da efetividade de descontaminação de ambientes marinhos por biossurfactantes têm sido estabelecidos. A efetividade de dispersão de petróleo por surfactina foi avaliada pela medida de CMC e da razão de dispersante/petróleo. Para a surfactina, os valores de CMC em água destilada deionizada foram mais baixos $\left(0,015\right.$ g.L - $\left.^{-1}\right)$ que na solução de sal marinho $(0,020$ g.L$\left.{ }^{1}\right)$, o que tem sido parcialmente atribuído às mudanças conformacionais induzidas pela salina em espécies iônicas solvatadas de biossurfactantes. A razão dispersante-petróleo para a surfactina foi de 1:96 em água, mais alta que em água do mar, de 1:30, sugerindo redução na eficiência de dispersão do petróleo em salina. ${ }^{36}$

Em relação aos efeitos do processo de biorremediação, no exame da biodegradação de diesel, avaliando dois biossurfactantes, surfactina e ramnolipídeo, observou-se que 0,04 g. $\mathrm{L}^{-1}$ de surfactina promoveu 94\% de biodegradação de diesel. ${ }^{28}$ Em estudos que avaliaram a ação da surfactina e ramnolipídeos na remoção de hidrocarbonetos totais de petróleo (TPH) do solo e compararam sua efetividade com surfactantes sintéticos, os resultados indicaram que a surfactina e o ramnolipídeo apresentaram eficiência de remoção de 62\% e 63\% de TPH em solo contaminado com 9.000 mg TPH $\mathrm{kg}^{-1}$ de solo seco. ${ }^{29}$ Esses resultados foram superiores à eficiência de remoção de petróleo por surfactantes sintéticos.

\subsection{BIOCONTROLE}

A atividade de biocontrole exercida pela surfactina compreende outra aplicação ambiental desse biossurfactante, a qual apresenta atividade bactericida e age de modo a desestabilizar a membrana fosfolipídica do fitopatógeno-alvo, resultando em lise da célula. O mecanismo de lise celular sugere que a surfactina é efetiva contra um amplo espectro de fitopatógenos, incluindo aqueles que têm desenvolvido resistência a agentes antimicrobianos específicos. Estudos relataram que a imunidade induzida por surfactina prepara a planta para resistir melhor à infestação do patógeno e envolve apenas expressão limitada de eventos moleculares relacionados à defesa e não provoca inibição de crescimento das mudas. ${ }^{30}$

\subsection{APLICAÇÕES TERAPÊUTICAS}

As surfactinas apresentam aplicações terapêuticas, como antimicoplasma, antibacteriana e antiviral, antiadesiva, antitumoral e de biocontrole.

Em decorrência da ação antimicoplasma, a surfactina pode atuar no Mycoplasma, um gênero de bactérias da família Mycoplasmataceae, que causa inflamação respiratória e doenças do trato urogenital. Antibióticos são ineficazes no tratamento dessas infecções, pois não podem penetrar em sua 
membrana citoplasmática. A efetividade da surfactina é atribuída à sua habilidade em formar canais condutores de íons em membranas da bicamada lipídica bacteriana por sua ação detergente, que inibe a atividade da enzima adenosina 3,5-monofosfato fosfodiesterase cíclica. ${ }^{31,33}$

A surfactina de $B$. subtilis possui atividade antibiótica potente, e aquela obtida de B. licheniformis inibe a germinação de Mycoplasma grisea. ${ }^{37}$ Considerando-se a natureza anfipática da surfactina, acredita-se que as atividades mencionadas são consequência direta da sua ação na integridade da bicamada lipídica. ${ }^{13}$

As características estruturais anfipáticas da surfactina possibilitam a sua interação em macromoléculas de membranas celulares, como enzimas e lipopolissacarídeos (LPSs). Pesquisadores têm estabelecido que a surfactina inibe o efeito inflamatório da interação direta de LPS com as células. Além disso, ela reduz os níveis de endotoxinas no plasma, fator de necrose tumoral em ratos que sofreram choque séptico, e, também, suprime a interação do lipídeo A com a proteína de ligação ao lipopolissacarídeo. ${ }^{11}$

As surfactinas também possuem propriedades antiadesivas que inibem a produção, a formação de biofilme por Salmonella typhimurium, Salmonella enterica, Escherichia coli e Proteus mirabilis e a adesão de bactérias em locais de infecção. Esse efeito pode ter aplicações biomédicas, particularmente em dispositivos cirúrgicos e implantes. ${ }^{5,11}$

A atividade antitumoral das surfactinas tem sido associada com a natureza hidrofóbica do ácido graxo que interage com a cadeia acil do fosfolipídeo ligado à membrana, e suas frações peptídicas interagem fortemente com as cabeças polares dos lipídeos, penetrando mais eficientemente nas membranas de células cancerosas. A surfactina inibiu as vias de sinalização fosfatidilinositol-3-quinase/serina-treonina quinase (PI3K/Akt) e proteína quinase ativada (MAPK) em células MCF-7 e reduziu a insaturação do ácido graxo na membrana da célula que conduz a apoptose celular em células de câncer de mama Bcap-37. ${ }^{38}$ A surfactina purificada do B. natto foi relatada pela primeira vez por possuir efeitos antitumorais em células do carcinoma de Ehrlich, e a surfactina purificada a partir da linhagem TK-1 inibiu células do câncer de mama MCF-7. A surfactina induziu a apoptose, e o ciclo celular parou na fase $\mathrm{G}_{2} / \mathrm{M}$ em células de câncer de mama MCF-7 como resultado da clivagem da caspase- 3 em células MCF-7. ${ }^{39}$

Pesquisadores relataram o efeito da surfactina na proliferação de células LoVo causadoras de carcinomas no cólon, bloqueando a proliferação dessas células por indução de atividade pro-ap e parada do ciclo celular. ${ }^{40}$ A propriedade anticâncer da surfactina ocorreu em razão da fragmentação de DNA, clivagem de PARP, ativação de caspase-3 e expressão alterada de muitas proteínas com o p21 $1^{\text {WAF1/Cip1 }}, \mathrm{p} 53$, quinase dependente de ciclina (CDK)2 e ciclina E. A atividade antiproliferativa da surfactina também foi mediada pela inibição da proteína cinase regulada por sinais extracelulares (ERK) e PI3K/Akt. ${ }^{40}$ 


\section{CONCLUSÃO}

A estrutura da surfactina, composta por uma porção hidrofílica (polar) e hidrofóbica (apolar), confere a capacidade de alterar as propriedades interfaciais e superficiais de um líquido. Tal propriedade propicia a ação da surfactina em diversas aplicações terapêuticas e ambientais, como na biorremediação, em tratamentos antibacterianos e outros. Porém, o alto custo de produção e recuperação da surfactina limita suas aplicações. Todavia, estratégias de fermentação podem ser empregadas para a síntese de surfactina por microrganismos, auxiliando o aumento do rendimento e a redução dos custos de produção de surfactina. Os resíduos agroindustriais são materiais de alto valor agregado e que podem ser utilizados em processos fermentativos para a produção de surfactina, além de contribuirem com a reutilização de material já processado. Além de resíduos agroindustriais, diferentes fontes de carbono e nitrogênio e elementos-traço também são empregados em fermentações em estado sólido para a produção de surfactina. Assim, técnicas fermentativas devem ser exploradas para a produção de surfactina em escala industrial.

\section{REFERENNCIAS}

1. Mulligan CN. Recent advances in the environmental applications of biosurfactants. J Colloid Interface Sci. 2009;14(5):372-78.

2. Acmite Market Intelligence. Global Surfactant Market. Market Report. 4th ed. Ratingen: Acmite Market Intelligence; 2016. 605 p.

3. Chen WC, Juang RS, Wei YH. Applications of a lipopeptide biosurfactant, surfactin, produced by microorganisms. Bioch. Eng. J. 2015;103:158-69. doi: 10.1016/j.bej.2015.07.009.

4. Arima K, Kakinuma A, Tamura G. Surfactin, a crystalline peptide-lipid surfactant produced by Bacillus subtilis, isolation, characterization and its inhibition of fibrin clot formation. Biochem Biophys Res Commun. 1968;31(3):488-94. doi: 10.1016/0006-291X(68)90503-2.

5. Sen R, Back N, Cohen IR, Lajtha A, Lambris JD, Paoletti R. Surfactin: Biosynthesis, Genetics and Potential Applications. In: Ramkrishna S, editor. Advances in Experimental Medicine and Biology. Biosurfactants. New York: Springer Science+Business media, LCC, Landes Bioscience; 2010, p. 316-323.

6. Slivinski CT. Produção de surfactina por Bacillus pumilus UFPEDA 448 em fermentação em estado sólido utilizando bagaço de cana e okara como substrato [tese]. Curitiba: Universidade Federal do Paraná; 2012. 143 p.

7. França IWL, Lima AP, Lemos JAM, Lemos CGF, Melo VM, Sant'ana HB, et al. Production of a biosurfactant by Bacillus subtilis ICA56 aiming bioremediation of impacted soils. Catalysis Today. 2015;255(5):10-5. doi: 10.1016/j.cattod.2015.01.046. 
8. Ayed HB, Hmidet N, Béchet M, Chollet M, Chataigné G, Leclère V, et al. Identification and biochemical characteristics of lipopeptides from Bacillus mojavensis A21. Process Biochem. 2014;49(10):1699-707. doi: 10.1016/j.procbio.2014.07.001.

9. Kakinuma A, Hori M, Isono M, Tamura G, Arima K. Determination of amino acid sequence in surfactin, a crystalline peptide lipid surfactant produced by Bacillus subtilis. Agric. Boil. Chem. 1969;33(12):971-72.

10. Liu XY, Yang S Z, Mu BZ. Isolation and characterization of a C12-lipopeptide produced by $B a$ cillus subtilis HSO 121. J. Pept. Sci. 2008;14(7):864-75. doi: 10.1002/psc.1017.

11. Seydlová G, Svobodová J. Review of surfactin chemical properties and the potential biomedical applications. Cent Eur J Med. 2008;3(2):123-33. doi: 10.2478/s11536-008-0002-5.

12. Liu X, Haddad NI, Yang S, Mu B. Structural characterization of eight cyclic lipopeptides produced by Bacillus subtilis HSO121. Protein Pept Lett. 2007;14(8):766-73. doi: 10.2174/092986607781483642.

13. Liu JF, Mbadinga SM, Yang SZ, Gu JD, Mu BZ. Chemical Structure, Property and Potential Applications of Biosurfactants Produced by Bacillus subtilis in Petroleum Recovery and Spill Mitigation. Int J Mol Sci. 2015;16(3):4814-37. doi: 10.3390/ijms16034814.

14. Yeh MS, Wei YH, Chang JS. Enhanced production of surfactin from Bacillus subtilis by addition of solid carriers. Biotechnol Prog. 2005;21(4):1329-34. doi: 10.1021/bp050040c.

15. Ghribi D, Ellouze-Chaabouni S. Enhancement of Bacillus subtilis Lipopeptide Biosurfactants Production through Optimization of Medium Composition and Adequate Control of Aeration. Biotechnol Res Int. 2011. doi: 10.4061/2011/653654.

16. Willenbacher J, Yeremchuk W, Mohr T, Syldatk C, Hausmann R. Enhancement of Surfactin yield by improving the medium composition and fermentation process. AMB Express. 2015;5(1):57. doi:10.1186/s13568-015-0145-0.

17. Faria AF, Teodoro-Martinez DS, Barbosa GNO, Vaz BG, Silva IS, Garcia JS, et al. Production and structural characterization of surfactin $\left(\mathrm{C}_{14} / \mathrm{Leu}_{7}\right)$ produced by Bacillus subtilis isolate LSFM-05 grown on raw glycerol from the biodiesel industry. Process Biochem. 2011;46(10):1951-57. doi: 10.1016/j.procbio.2011.07.001.

18. Sousa M, Dantas IT, Felix AKN, Sant’ana HB, Melo VMM, Gonçalves, LRB. Crude Glycerol from Biodiesel Industry as Substrate for Biosurfactant Production by Bacillus subtilis ATCC 6633. Braz Arch. Biol Technol. 2014;57(2):295-301. doi: 10.1590/S1516-89132014000200019.

19. Gudiña EJ, Fernandes EC, Rodrigues AI, Teixeira JA, Rodrigues LR. Biosurfactant production by Bacillus subtilis using corn steep liquor as culture médium. Front Microbiol. 2015;6:59. doi: 10.3389/fmicb.2015.00059. 
20. Vedaraman N, Venkatesh N. Production of surfactin by bacillus subtilis MTCC 2423 from waste frying oils. Braz. J. Chem. Eng. 2011;28(2):175-80. doi: 10.1590/S0104-66322011000200001.

21. Elazzazy AM, Abdelmoneim TS, Almaghrabi OA. Isolation and characterization of biosurfactant production under extreme environmental conditions by alkali-halo-thermophilic bacteria from Saudi Arabia. Saudi J Biol Sci. 2015;22(4):466-75. doi: 10.1016/j.sjbs.2014.11.018.

22. Sen R, Swaminathan T. Characterization of concentration and purification parameters and operating conditions for the small-scale recovery of surfactin. Process Biochem. 2005;40(9):2953-8. doi: 10.1016/j.procbio.2005.01.014

23. Fahim S, Dimitrov K, Vauchel P, Gancel F, Delaplace G, Jacques P, et al. Oxygen transfer in three phase inverse fluidized bed bioreactor during biosurfactant production by Bacillus subtilis. Biochemical Engineering Journal. 2013;76:70-6. doi: 10.1016/j.bej.2013.04.004.

24. Wei YH, Lai CC, Chang JS. Using Taguchi experimental design methods to optimize trace element composition for enhanced surfactin production by Bacillus subtilis ATCC 21332. Process Biochem. 2007;42:40-5. doi: 10.1016/j.procbio.2006.07.025

25. Konishi M, Yoshida Y, Horiuchi JI. Efficient production of sophorolipids by Starmerella bombicola using a corncob hydrolysate medium. J Biosci Bioeng. 2015;119(3):317-22. doi: 10.1016/j. jbiosc.2014.08.007.

26. Marin CP, Kaschuk JJ, Frollini E, Nitschke M. Potential use of the liquor from sisal pulp hydrolysis as substrate for surfactin production. Ind Crops Prod. 2015;66:239-45. doi: 10.1016/j. indcrop.2015.01.001.

27. Rivera OMP, Moldes AB, Torrado AM, Domínguez JM. Lactic acid and biosurfactants production from hydrolyzed distilled grape marc. Process Biochem. 2007;42(6):1010-20. doi: 10.1016/j. procbio.2007.03.011.

28. Whang LM, Liu PW, Ma CC, Cheng SS. Application of biosurfactants, rhamnolipid, and surfactin, for enhanced biodegradation of diesel-contaminated water and soil. J Hazard Mater. 2008;151(1):155-63. doi: 10.1016/j.jhazmat.2007.05.063.

29. Lai CC, Huang YC, Wei YH, Chang JS. Biosurfactant-enhanced removal of total petroleum hydrocarbons from contaminated soil. J Hazard Mater. 2009;167(1-3):609-14. doi: 10.1016/j. jhazmat.2009.01.017

30. Debois D, Fernandez O, Franzil L, Jourdan E, De Brogniez A, Willems L, et al. Plant polysaccharides initiate underground crosstalk with bacilli by inducing synthesis of the immunogenic lipopeptide surfactin. Environ Microbiol Rep. 2015;7(3):570-82. doi: 10.1111/1758-2229.12286.

31. Heerklotz H, Wieprecht T, Seelig J. Membrane perturbation by the lipopeptide surfactin and detergents as studied by Deuterium NMR. J Phys Chem. 2004;108(15):4909-15. doi: 10.1021/ jp0371938. 
32. Rosenberg E, Ron EZ. High- and low-molecular-mass microbial surfactants. App Microbiol Biotechnol. 1999;52(2):154-62. doi: 10.1007/s002530051502.

33. Chen H L, Chen YS, Juang RS. Recovery of surfactin from fermentation broths by a hybrid salting-out and membrane filtration process. Sep Purif Technol. 2008;59(3):244-52. doi:10.1016/j. seppur.2007.06.010.

34. Makkar RS, Cameotra SS. Structural characterization of a biosurfactant produced by Bacillus subtilis at $45^{\circ} \mathrm{C}$. J Surfactants Deterg. 1999;2(3):367-72. doi:10.1007/s11743-999-0091-6.

35. Schaller KD, Fox S, Bruhn D, Noah, K, Bala G. Characterization of surfactin from Bacillus subtilis for application as an agent for enhanced oil recovery. App Biochem Biotechnol. 2004;113116:827:36.

36. Marti ME, Colonna WJ, Patra P, Zhang H, Green C, Reznik G, et al. Production and characterization of microbial biosurfactants for potential use in oil-spill remediation. Enzyme Microb Technol. 2014;55:31-39. doi: 10.1016/j.enzmictec.2013.12.001.

37. Tendulkar SR, Saikumari YK, Patel V, Raghotama S, Munshi TK, Balaram P, et al. Isolation, purification and characterization of an antifungal molecule produced by Bacillus licheniformis BC98, and its effect on phytopathogen magnaporthe grisea. J Appl Microbiol. 2007;103(6):2331-39. doi: 10.1111/j.1365-2672.2007.03501.x.

38. Liu XY, Tao X, Zou A, Yang S, Zhang L, Mu B. Effect of the microbial lipopeptide on tumor cell lines: apoptosis induced by disturbing the fatty acid composition of cell membrane. Protein Cell. 2010;1(6):584-94. doi:10.1007/s13238-010-0072-4.

39. Cao XH, Liao Zy, Wang Cl, Cai P, Yang WY, Lu MF, et al. Purification and antitumour activity of a lipopeptide biosurfactant produced by Bacillus natto TK. Biotechnol Appl Biochem. 2009;52(2):97-106. doi: 10.1042/BA20070227.

40. Kim SY, Kim JY, Kim SH, Bae HJ, Yi H, Yoon SH, et al. Surfactin from Bacillus subtilis displays anti-proliferative effect via apoptosis induction, cell cycle arrest and survival signaling suppression. FEBS Lett. 2007;581(5):865-71. doi: 10.1016/j.febslet.2007.01.059.

Data da submissão: 22 de agosto de 2017 Avaliado em: 08 de outubro de 2017 (AVALIADOR A) Avaliado em: 27 de outubro de 2017 (AVALIADOR B) Aceito em: 28 de novembro de 2017 